\title{
Pregnancy with uterine perforation: A case report
}

\section{Hana Sohrabi ${ }^{1}$ Sevedeh Revhaneh Yousefi Sharmi ${ }^{2}$}

1. MSc student in midwifery education, Midwifery Department, School of Nursing and Midwifery, Kurdistan University of Medical Sciences, Sanandaj, Iran. ORCID ID: 0000-0001-8568-8286

2. Assistant Professor, Obstetrics and Gynecology Department, Medical School, Kurdistan University of Medical Sciences, Sanandaj, Iran, (Corresponding Author), Tel: 087-33285910, Email: Yousefi805@yahoo.com. ORCID ID: 0000-0002-40504137

\begin{abstract}
Background and Aim: Occurrence of pregnancy in a perforated uterus is a rare phenomenon and can have serious consequences. Absence of peritoneal symptoms may be due to healthy amniotic membranes and lack of extrusion of intra-abdominal pregnancy products. Bleeding may be vaginal or inside the abdominal pelvic cavity. We report a case of pregnancy in a perforated uterus in a woman with history of curettage in the last year.

Case presentation: A 38-year-old woman, gravid 1, with gestational age of 36 weeks and 4 days, was admitted to "Besat Hospital" in Sanandaj with complaint of labor pain and reduced fetal movement. The patient had a history of endometrial polyp removal through curettage surgery in the last year, and underwent emergency cesarean section due to recurrent variations in the fetal heart rate and fetal distress. During the cesarean section, we noticed a hole measuring $3 \times 3 \mathrm{~cm}$ and an apparently healthy live baby boy. The baby was born with an Apgar score of $\frac{9}{10}$. The hole in the fundus of the uterus was repaired.

Conclusion: Pregnancy with perforated uterus and birth of a healthy baby in such condition are rare phenomena. In order to reduce the incidence rates of maternal mortality and loss of pregnancy products in gynecological surgeries, such as curettage, at reproductive age more care is required.
\end{abstract}

Keywords: Pregnancy, Uterine perforation, Uterine cavity, Curettage, Polyps, Nulligravid.

Received: June 2, 2020

Accepted: Dec 15, 2020

How to cite the article: Hana Sohrabi, Seyedeh Reyhaneh Yousefi Sharmi. Pregnancy with uterine perforation: A case report. SJKU 2021;25(6):127-132.

Copyright (C) 2018 the Author (s). Published by Kurdistan University of Medical Sciences. This is an open access article distributed under the terms of the Creative Commons Attribution-Non Commercial License 4.0 (CCBYNC), where it is permissible to download, share, remix, transform, and buildup the work provided it is properly cited. The work cannot be used commercially without permission from the journal 


\section{باردارى با رحم سوراخ: تزارش مورد}

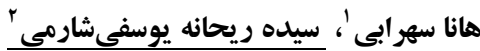

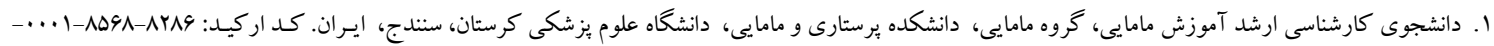

r. استاديار، كروه زنان و زايمان، دانشكده يزشكى، دانشكاه علوم بزشكى كردستان، ستندج، ايران. بست الكترونيكك: Yousefi 805@ yahoo.com ، تلفـن

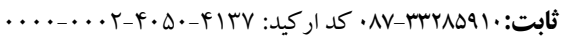

\section{جكيده}

زمينه و هدف: بروز حاملكى با وجود باركى رحم يك بديده نادر است و مى تواند عواقب جدى داشته باشد. عدم وجود علايم

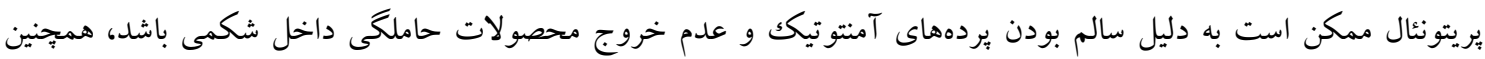

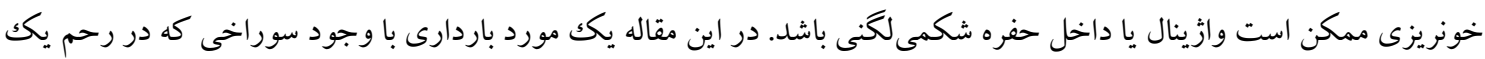

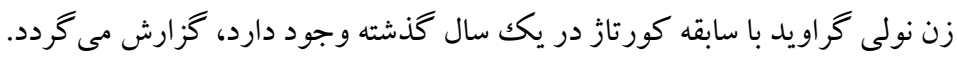

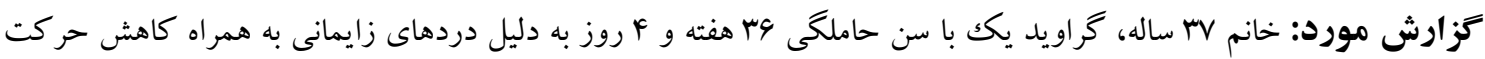

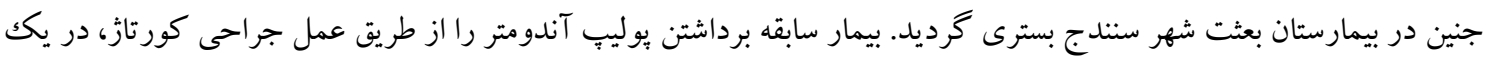

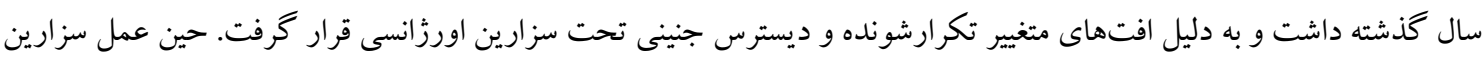

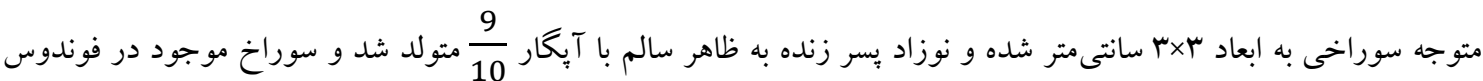
رحم ترميم كرديد. نتيجه كيرى: باردارى و تولد يك كود كك سالم با رحم سوراخ شده بديدهاى نادر است. براى كاهش مر گك و مير مادران و از بين

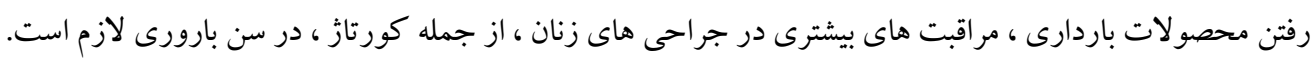

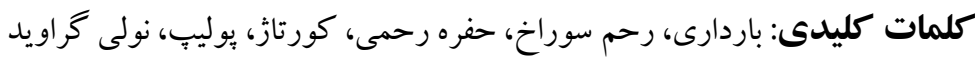

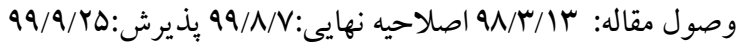



كاهش يافته بود. بِ از اخذ نوارقلب جنين در بيمارستان دهكلان و غيرواكنشى (Non-Reactive) بودن آن، بيمار

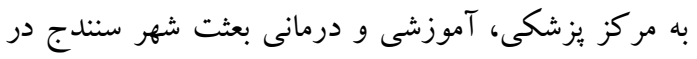

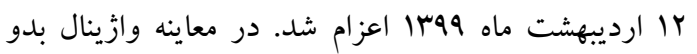

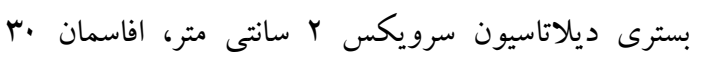
درصد، جايگاه ץ-، عضو نمايش سفاليك، كيسه آب سالم، ضربان قلب جنين و علايم حياتى مادر نرمال بود. معاينه لكنى محدوديتى نداشت. بيمار سابقهى برداشتن بوليب

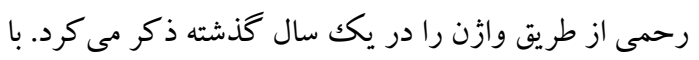

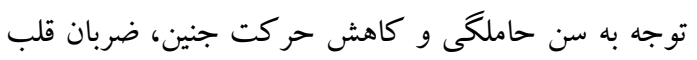

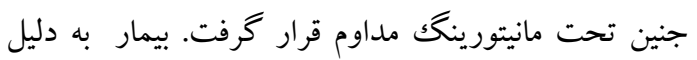

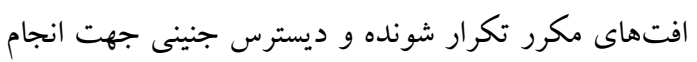

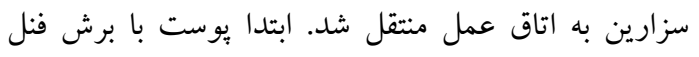

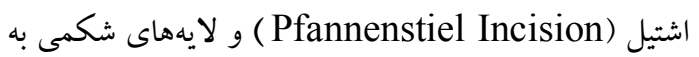
ترتيب آناتوميكك باز شدند و سبس برش در سگمان تحتانى

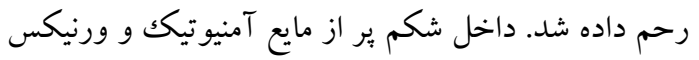

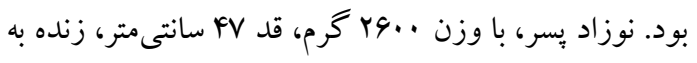

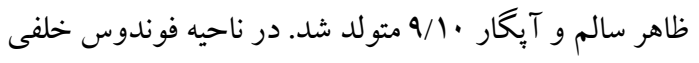
رحم سوراخى به ابعاد r ×r سانتىمتر كه به بريتوئن راه

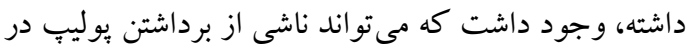

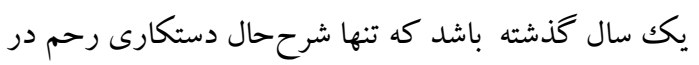
خانم بود. جفت و يردههاى جنينى به طور كامل خارج شد و

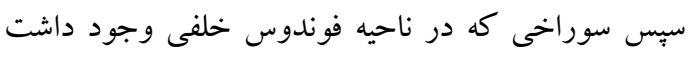

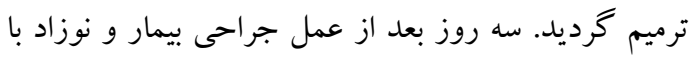

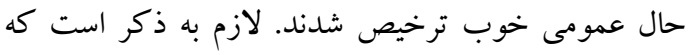

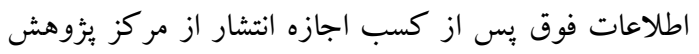

$$
\text { بيمارستان بعثت ارائه گرديد. }
$$

مقدمه وقوع باردارى و به نتيجه رسيدن آن با وجود يارگى رحم بديدهاى نادر است اما بطور بالقوه مىتواند بيامدهاى

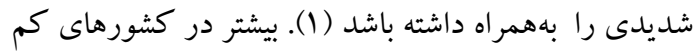

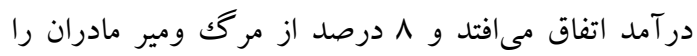
تشكيل مىدهد (Y). مهمترين عارضه ديلاتاسيون و كورتاز،

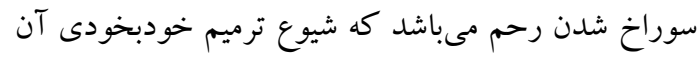

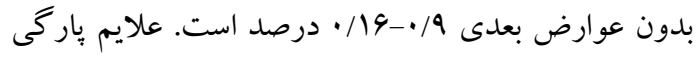
رحم در باردارى، ضربان قلب غيرطبيعى جنين، درد مداوم

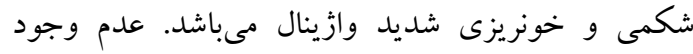

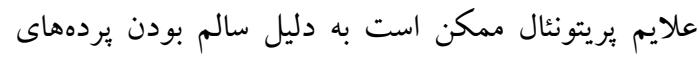

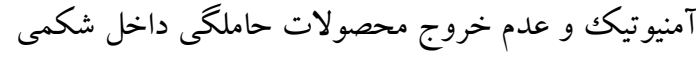

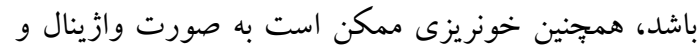

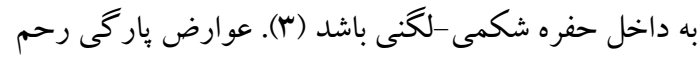

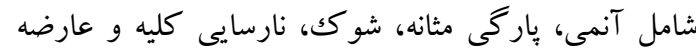

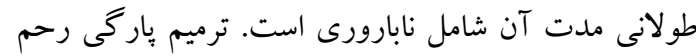

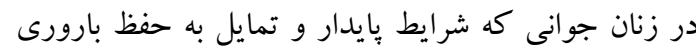

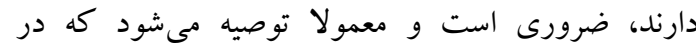
باردارىهاى بعدى سزارين الكتيو در 4س هفتخى انجام شود

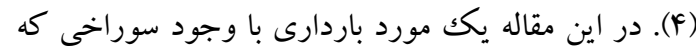
در رحم يكك زن نولى گراويد با سابقه كورتاث در يك سال

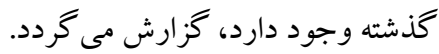

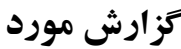

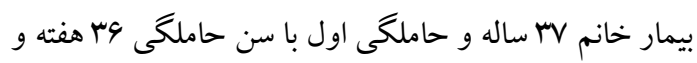

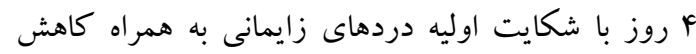

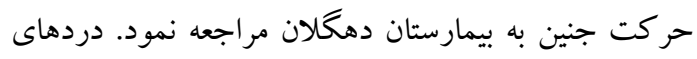
زايمانى به صورت تشديد شونده بوده و فو اصل زمانى دردها 



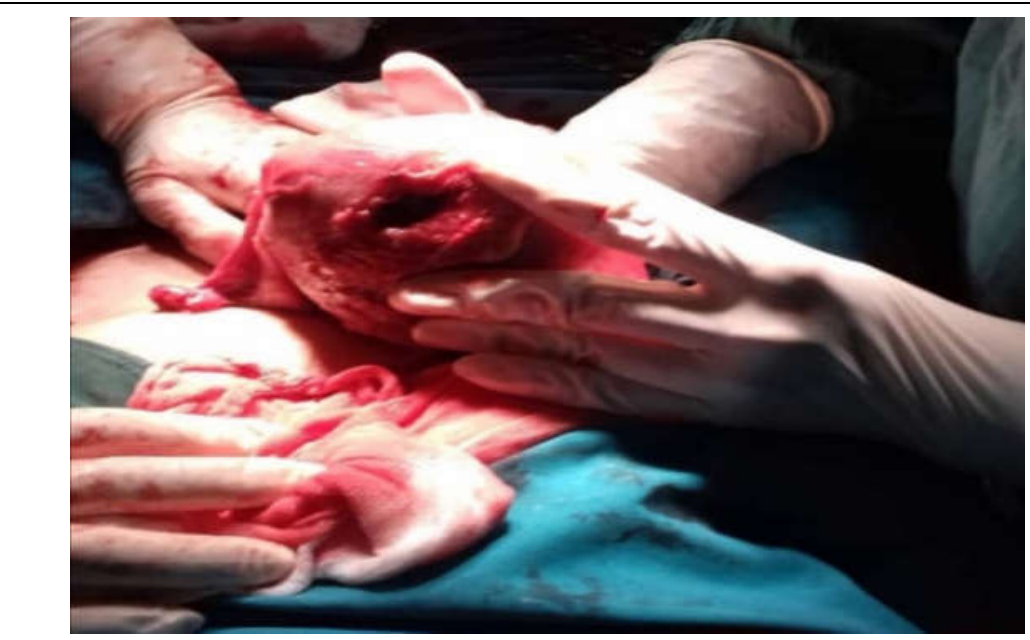

شكل 1. تصوير يرفوريشن رحم. اين تصوير سوراخى به ابعاد ب × س سانتىمتر در فوندوس رحم را نشان مىدهد.

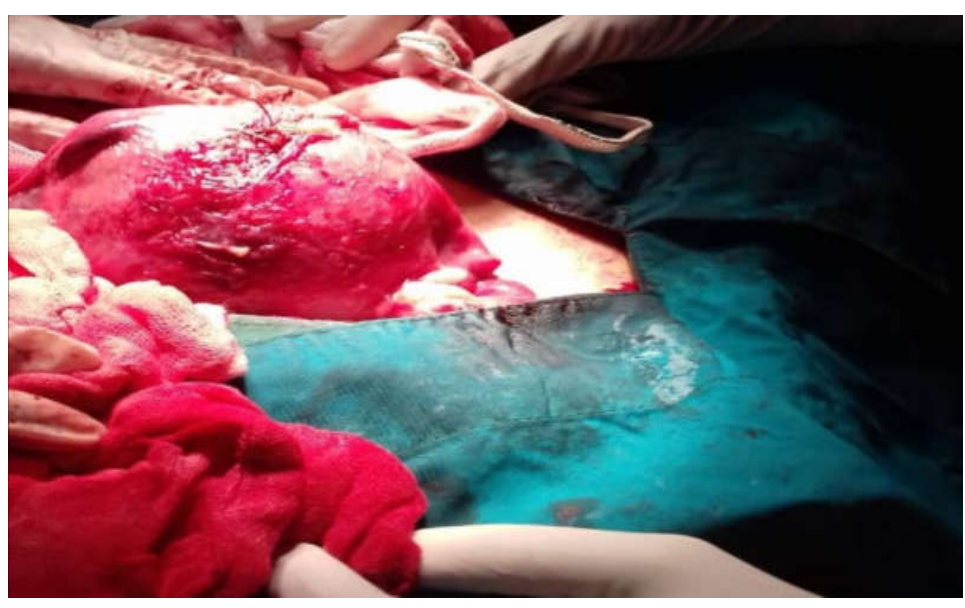

شكل r. تصوير ترميم يرفوراسيون رحم.

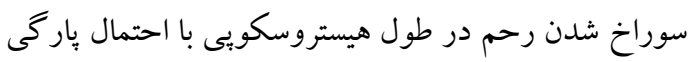
رحم در حاملكىهاى بعدى همراه است (A). همجنين يوليِهاى آندومتر تعداد زيادى غده و استروما در قسمت

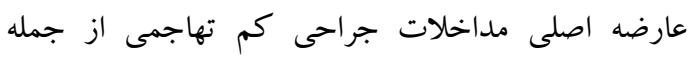
داخلى رحم مىباشند كه در سنين بارورى شايع هستند (ه).

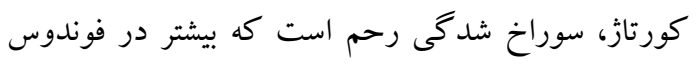
رحم رخ مىدهد. اين عارضه بيشتر در سقطهاى سه ماهد

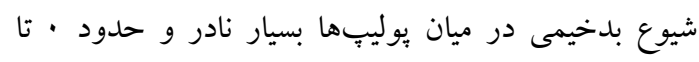

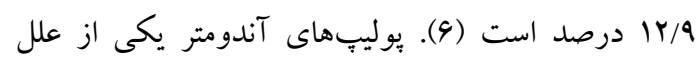

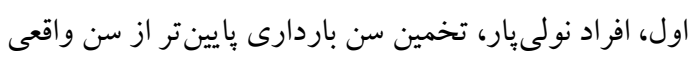
خونريزى در فواصل بين قاعدگى، خونريزى شدريد

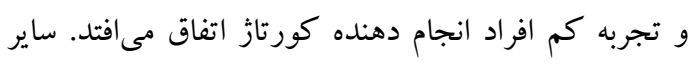

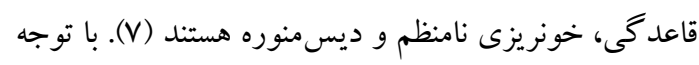

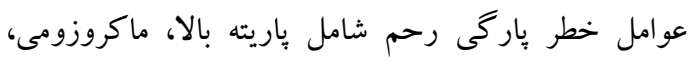

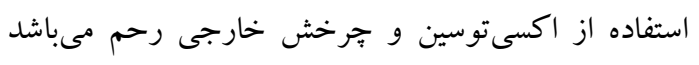

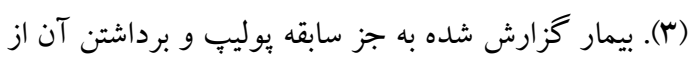

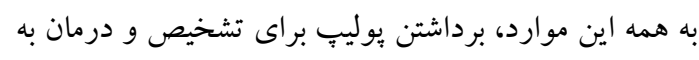

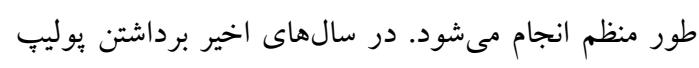
با استفاده از هيستروسكويى و كور انجاز رايج است (9). طريق كورتاز ريسك فاكتور ديخرى نداشت. 
1.Islam A, Ali Shah A, Jadoon H, Fawad A, Javed M, Un A, et al. A two-year analysis of uterine rupture in pragnancy. J Ayub Med Coll Abbottabad. 2018;30(4):639-641.

2.Gebretsadik A, Hagos H, Tefera K. Out come of uterine rupture and associated factors in yirgalem general and teaching hospital, southern Ethiopia: a crossectional study. BMC Pregnancy Childbirth. 2020; 20(256):1-7.

3.Shirazi M, Rahimi Shaar-Baf F, Moosavi S. Rupture of an unscarred uterus in a nullipar pregnant women with a history of curettage: Case report. TUMJ. 2015;73(2):138-142.

4.Khan N, Gul H, Qdir M. Predisposing factors and outcome in patients with ruptured uterus.JSMC. 2019;9(2):233-237.

5. Selam B, Danismah N, Ekemen S, Bircan C. Endometrial polyp in early pregnancy ending with term labor. ACU Saglik Bil Derg. 2020;11(1):68-71.

6. Lee M. Endometrial polyp removed by a manual hystroscopic tissue removed device. GMIT. 2020; 9(1): 34-35. 
7. Berek J, Berek D. Berek and Novaks Gynecology. 1nd ed. Tehran. Golban, 2018:238-239.

8. Uccella S, Cromi A, Bogani G, Zaffaroni E, Ghezzi F. Spontaneous prelabor uterine rupture in a primigravida: a case report and review of literature.AJOG.2011;205(5):6-8.

9.Bouzari Z, Mohammadnetaj M, Ghanbarpour A. Successful pregnancy and delivery after uterine rupture in previous pregnancy: A Case Report. J Babol Univ Med Sci.2019;21:345-348.

10.Conturso R, Redaelli L, Pasini A, Tenore A. Spontaneous uterine rupture with amniotic sac protrussion at 28 weeks subsequent to previous hysteroscopic metroplasty. Eur J Obstet Gynecol Reprod Biol. 2003;107:98-100.

11.Cunningham F, Leveni K, Bloom S, Spong C, Dashe L, Hoffman M. Williams Obstetrics. 25nd ed. Tehran. Golban,2018:434-436. 